\title{
Managing Decubitus ulcers During COVID-19 Outbreak is even more Challenging
}

\author{
Perçin Karakol, (i) Mehmet Bozkurt
}

Department of Plastic, Reconstructive and Aesthetic Surgery, University of Health Sciences Turkey, Bağcılar Training and Research Hospital, Istanbul, Turkey

\begin{abstract}
Introduction: The World Health Organization declared the outbreak of coronavirus 2019 (COVID-19) a pandemic on March 11, 2020. The service delivery capacity of the health system around the world was quickly overwhelmed, primarily due to the influx of patients with respiratory symptoms due to COVID-19 and the precautions required to prevent spread of the highly infectious virus. The treatment of pressure ulcers in inpatient services, intensive care units, and palliative care units can be very challenging and costly at the best of times; however, hospitals had to adapt quickly to new and difficult circumstances.

Methods: Patients were treated at home as much as possible to reduce hospital stay and visits. The wounds of hospitalized patients were closed as soon as it was feasible and patients were discharged and followed up at home. Guidance was provided regarding the use of isolation and N95 masks to prevent infection and the prevention of new wounds. Existing wounds were reconstructed with single-session surgeries as much as possible.

Results: Primary treatment at home, limited surgical repair, and the observance of specific precautions almost certainly reduced the number of cases of COVID-19 infection. Treatment with silver dressings and vacuum-assisted closure were effective infection control measures and allowed for the practical allocation of limited hospital resources.

Discussion and Conclusion:The training provided by public hospital training units to wound care personnel, home care service personnel, and family members was successful and valuable. Existing wounds were closed and new wounds were prevented. This vulnerable patient population was protected as a result of a thorough and proactive approach applied during a difficult period.

Keywords: COVID-19; decubitus ulcer; pressure ulcer; SARS-CoV-2.
\end{abstract}

$\mathrm{D}$ ecubitus ulcers; are wounds happening in patients who have to stay at a certain position continuously. Pressure between the bed and the bone is not the only cause in the areas where they come into contact with the bed. Especially since they are located under the bone, they also occur due to friction. Although there are different pathophysiology mechanisms at the bottom, main defect is deterioration of skin oxygenation ${ }^{[1]}$. In patients with neurological defects, who are not well fed, who are constantly infected with fecal incontinence or urine, it is already very difficult to manage the process under normal conditions ${ }^{[2]}$. Being bed-bound, most of these patients need someone else to ensure their nutrition and personal hygiene. In this sense, public hospitals have undertaken tasks such as pre-

Correspondence (İletişim): Perçin Karakol, M.D. Saglik Bilimleri Universitesi, Bagcilar Egitim Arastirma Hastanesi, Plastik Rekonstruktif ve Estetik Cerrahi Anabilim Dali, İstanbul, Turkey

Phone (Telefon): +90 5353965535 E-mail (E-posta): ppercin@gmail.com

Submitted Date (Başvuru Tarihi): 11.07.2020 Accepted Date (Kabul Tarihi): 11.08.2020

Copyright 2021 Haydarpaşa Numune Medical Journal

OPEN ACCESS This is an open access article under the CC BY-NC license (http://creativecommons.org/licenses/by-nc/4.0/) 
venting wounded patients from worsening with COVID-19 infection, and then providing training for follow-up of such patients at home ${ }^{[3]}$.

\section{Materials and Methods}

After covid-19 outbreak announcement; During the COVID-19 outbreak, changes which are explained below were made to manage decubitus ulcers in wound clinics within the scope of public hospitals. The main problem for these patients is that they have to stay still and maintain the same position for a long time. In the approach to decubitus ulcers, where clinical manifestations can be completely different, the first treatment goal is to prevent infection and new wound opening by providing partial movement. In addition, after the global COVID-19 outbreak, the need to maintain social distance has made it more difficult to treat or care for these patients and has created a problem (Fig. 1). After the declaration of an outbreak and the diagnosis of the first COVID case in the country, a curfew was imposed on people over the age of 65 and under the age of 20 in line with health policies. In this way, only the group of patients with the chance to mobilize with a wheelchair were also restricted to the house. In this way, the restriction of their movements automatically increased the growth of decubitus ulcer. In order to avoid decubitus ulcer formation in such patients, use of cushions in anti-pressure gel or foam form, home type rehabilitation movements, and simple manipulations to change position were advised through public spotlight applications and online guides ${ }^{[4]}$.

Another group of bed-dependent decubitus ulcer patients which are normally monitored by the professional home care team were started to be monitored at home by consulting plastic surgery specialists and wound care specialists with mobile phone applications by professional teams and by taking blood tests for infection tracking at home. Since many of these patients were chronically ill, their defects contained, skin, subcutaneous area, fat, fascia and muscle (Fig. 2). In the wound care of these patients with deep tissue loss, to prevent the medical team from coming home every day and to reduce the risk of COVID-19 transmission, switching was made to colloid, silver products that could be changed every 4-5 days depending on the level of exudation ${ }^{[5]}$. Records were checked to deliver air beds that dissipate pressure to such patients; in accordance with the parameters of infection, the appropriate antibiotheraphies were prescribed through the system by studying antibiogram from blood and wound cultures.

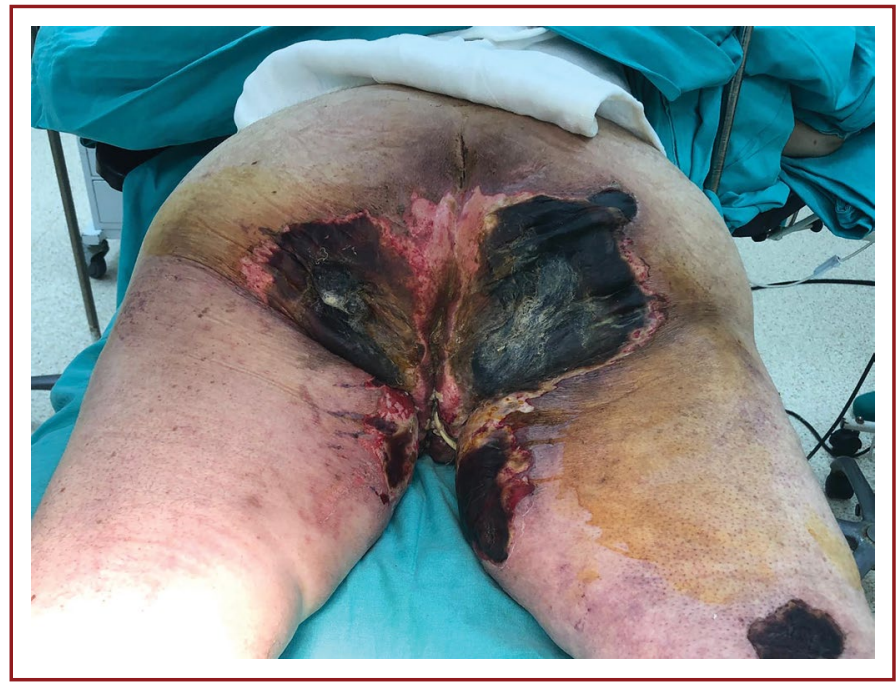

Figure 1. A pressure wound, with multiple defects that can become mortal and definitely needs hospitalization.

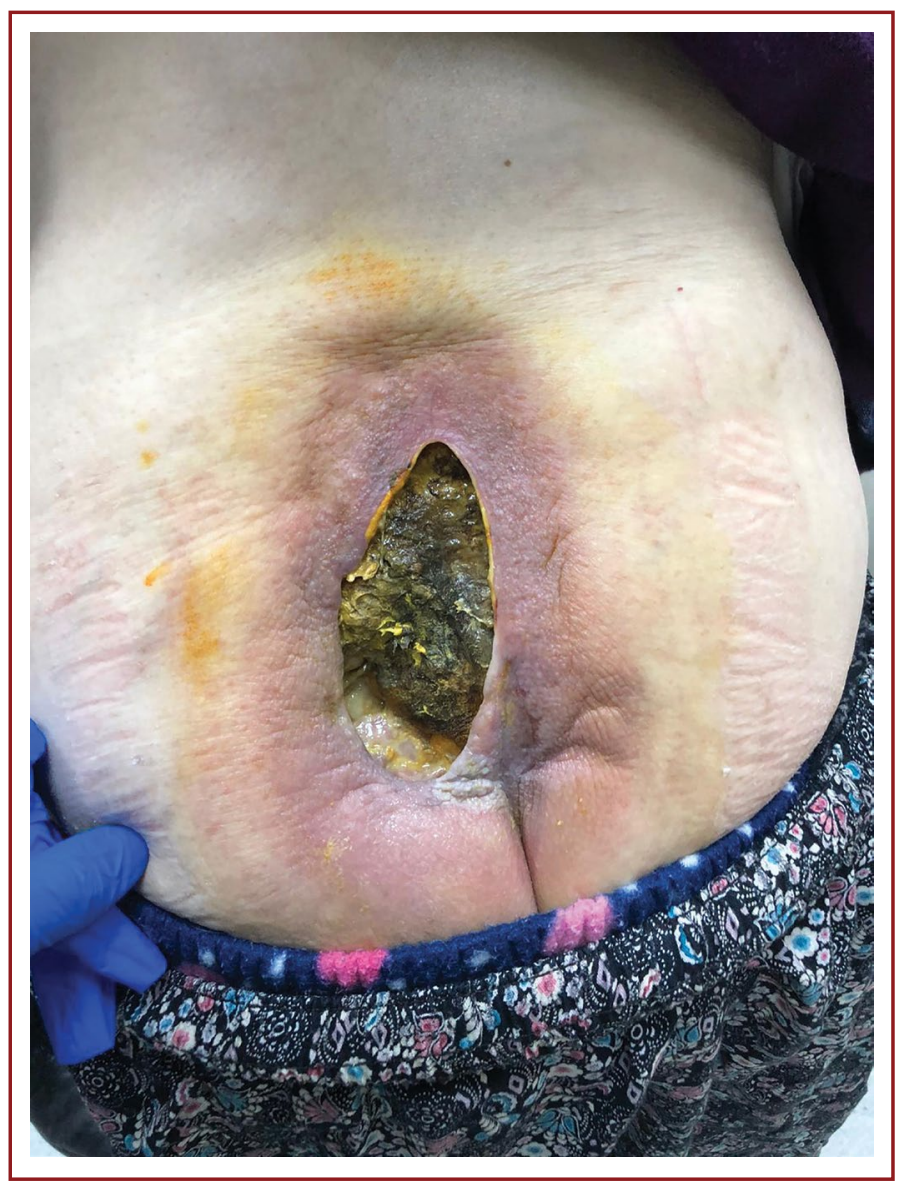

Figure 2. Severe pressure wound treating by home care team at home.

To reduce the rate at which such wound care patients are brought to the hospital, switching was made to enzymatic debridement with creams after minimal surgical debridement for necrotic defects and then to the application of 
VAC (Vacuum Assisted Closure) ${ }^{[6]}$. Additional canisters and collection sets were left in homes to prevent any VAC congestion $^{[7]}$.

\section{Results}

To prevent the inpatient from contacting with active adult individuals from the outside, in addition to the use of the N95 mask, informative training was given to the household about visiting prohibitions the use of separate rooms. On the other hand, for patients who are being treated in intensive care, palliative care or services who have decubitus ulcer in addition to other illnesses, precautions such as visitor prohibitions and transforming rooms into single and isolated rooms were taken and similarly silver colloid wound care materials to be changed twice a week were used and it was ensured that infection parameters are closely monitored. Local dressing materials with antibacterial effectiveness were generally preferred. Within this group of patients, those with debridement requirements were treated in local surgery rooms or at bedsides with surgical sets instead of in operating rooms. VAC treatment of many patients was continued in such a way as not to prevent frequent position change.

In order to prevent infection after contamination with gaita, personal hygienic care and practices to decrease patient mortality, meeting of patients' daily calorie and protein needs was carried out selflessly by nurses and auxiliary medical staff.

Among all of these groups of patients those requiring an operation, whose wounds did not heal despite auxiliary treatment, were taken into operation by connecting negative and positive ones to different machines after their PCR analysis for COVID-19, lung tomography and general routine anesthesia lab prompts and the approval of their anesthesia was taken ${ }^{[8]}$. During all patient surgeries, the surgical team went into surgery with full protection gear including glasses, shield, surgical gloves, surgical clothing, etc (Fig. 3). At the process of closing the defect, in terms of plastic surgery, single-stage flap applications were generally preferred (Fig. 4) ${ }^{[9]}$. Graft applications and multiple drain placements were specifically avoided. In order not to take patients into the operating room for a second time, hemostasis was carefully performed.

\section{Discussion}

Although they can occur all over the body, $95 \%$ of decubitus ulcers, most commonly occur in the lower half of the body. In fact, the main factor determining the region

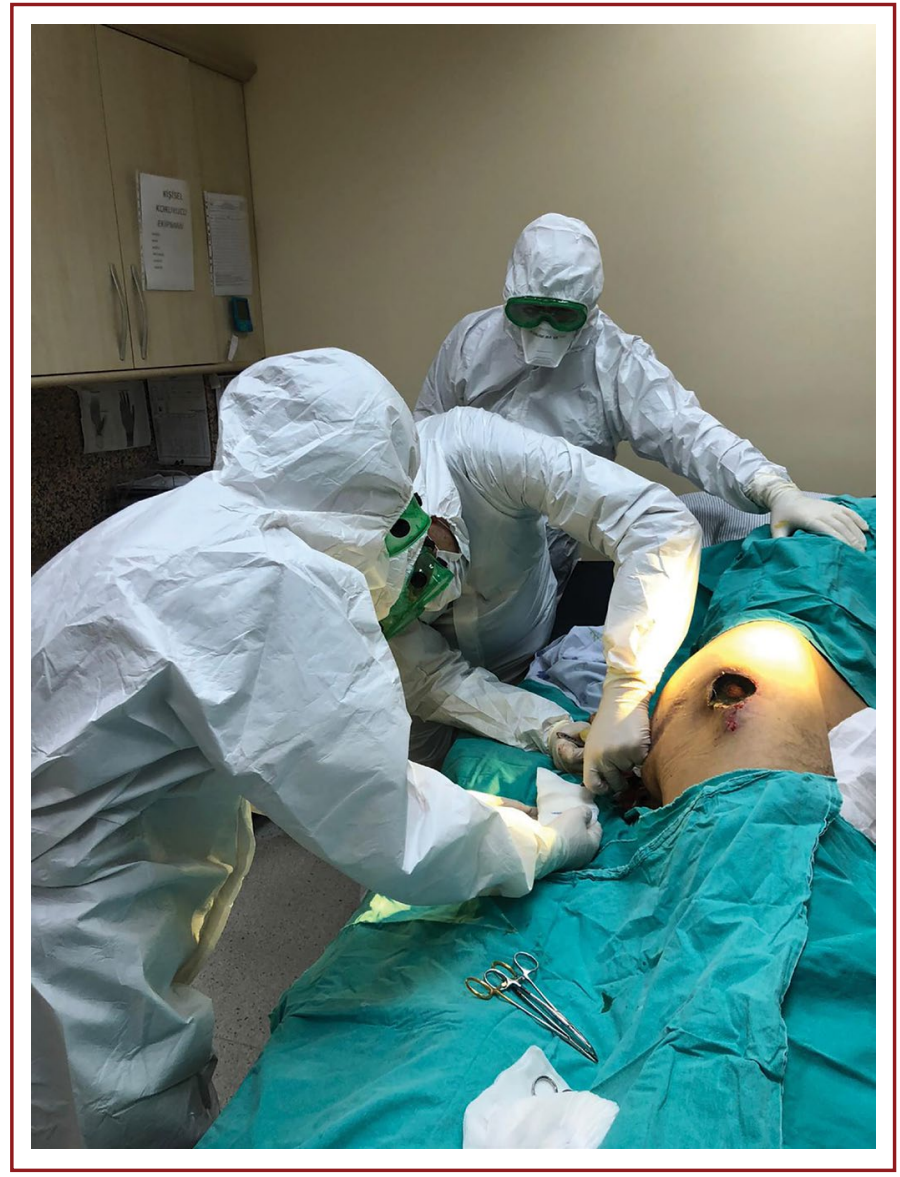

Figure 3. A wound team that has taken all precautions against COVID-19, performing debridement in the local intervention room.

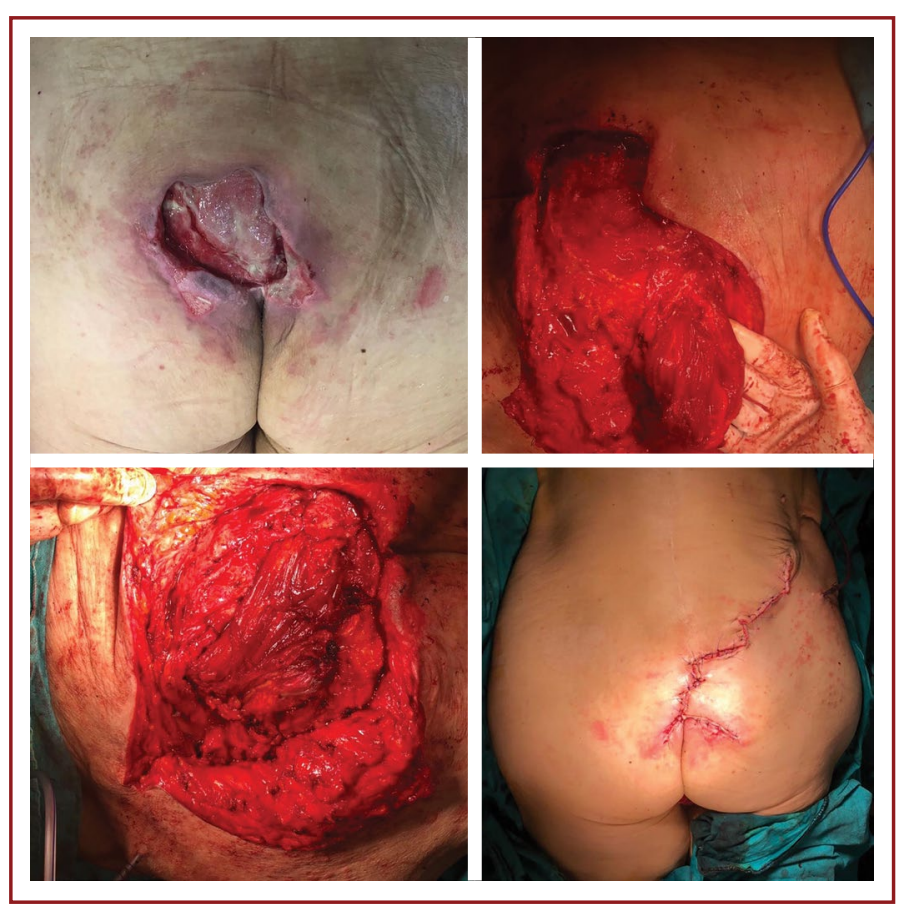

Figure 4. It closed with musculocutaneous flap in a single session that pressure wound with granulation tissue. 
where decubitus ulcers occur is the patient's hospitalization position. If the patient lies in supine position, it occurs mostly sacral (50\%), heel (15\%) and trochanteric (10\%) on the fields, and less frequently on the thoracic or occipital regions ${ }^{[10]}$. The skin findings can range from mild hyperemia to deep necroses which descend to the bone including full layer soft tissue and muscle, and skin defects ${ }^{[11]}$. In the deep tissue cultures of these patients, different grams positive or different anaerobic microorganisms especially Enterobacter, Staph spp, Enterococcus faecalis can reproduce $^{[12]}$. Contamination of the wounds with urine and gaita makes wounds worse. In home education of patient relatives, the emphasis was placed on preventing contamination of the press as well as preventing it. Normally, surgical debridement is as important in closure of such wounds as dressings and VAC application. In wounds that are ready after debridement, the defects are closed with a single session or multiple sessions, especially flap applications. During the pandemic period, patients with ready wound beds were hospitalized and single-session applications were preferred.

The "14 days of medical observation" rule should never be forgotten. Within the surgical wound team, the staff with contact history should leave the team and their contact with other patients and medical personnel should be cut off ${ }^{[3,8]}$. In terms of predisposition to infection, everything needed should be done in order to reduce the frequency of hospital visits by these pressure wound patients who already have open wounds in order not to increase their morbidity and mortality ${ }^{[13]}$.

\section{Conclusion}

Maximum attention and care is required to ensure that the need for an operating room, and contact with other patients are reduced for patients who are already hospitalized and if possible that extra wounds are not opened.

Ethics Committee Approval: Written consent was obtained from the ethics committee formed by the Ministry of Health for the covid period clinical studies (date: 16.05.2020, number: 2020-23).

Peer-review: Externally peer-reviewed.

Authorship Contributions: Concept: P.K., M.B.; Design: P.K., M.B.; Data Collection or Processing: P.K., M.B.; Analysis or Interpretation: P.K., M.B.; Literature Search: P.K., M.B.; Writing: P.K., M.B.
Conflict of Interest: None declared.

Financial Disclosure: The authors declared that this study received no financial support.

\section{References}

1. Cichowitz A, Pan WR, Ashton M. The heel: anatomy, blood supply, and the pathophysiology of pressure ulcers. Ann Plast Surg 2009;62:423-9. [CrossRef]

2. Brown KL, Phillips TJ. Nutrition and wound healing. Clin Dermatol 2010;28:432-9. [CrossRef]

3. Ma S, Yuan Z, Peng Y, Chen J, Li H, Luo Q, et al. Experience and suggestion of medical practices for burns during the outbreak of COVID-19. Burns 2020;46:749-55. [CrossRef]

4. Hahnel E, El Genedy M, Tomova-Simitchieva T, Hauß A, Stroux $A$, Lechner $A$, et al. The effectiveness of two silicone dressings for sacral and heel pressure ulcer prevention compared with no dressings in high-risk intensive care unit patients: a randomized controlled parallel-group trial. $\mathrm{Br} J$ Dermatol 2020;183:256-64. [CrossRef]

5. Apirag C, Peerasak C, Jupaporn K. Cost-effectiveness analysis in comparing alginate silver dressing with silver zinc sulfadiazine cream in the treatment of pressure ulcers. Arch Plast Surg 2013;40:589-96. [CrossRef]

6. Mataro I, Lanza A, Di Franco S, Di Franco L, Sangiuolo M, Notaro $\mathrm{M}$, et al. Releasing burn-Induced compartment syndrome by enzymatic escharotomy-debridement: a case study. J Burn Care Res 2020;41:1097-103. [CrossRef]

7. Batra RK, Aseeja V. VAC therapy in large infected sacral pressure ulcer grade iv can be an alternative to flap reconstruction? Indian J Surg 2014;76:162-4. [CrossRef]

8. Forrester JD, Nassar AK, Maggio PM, Hawn MT. Precautions for operating room team members During the COVID-19 pandemic. J Am Coll Surg 2020;230:1098-101. [CrossRef]

9. Surajit B, Mishra K. Pressure ulcers: current understanding and newer modalities of treatment. Indian J Plast Surg 2015;48:416. [CrossRef]

10. Dincer M, Doger C, Tas SS, Karakaya D. An analysis of patients in palliative care with pressure injuries. Niger J Clin Pract 2018;21:484-91. [CrossRef]

11. Cox J, Schallom M. Pressure injuries in critical care: a survey of critical care nurses. Crit Care Nurse 2017;37:46-55. [CrossRef]

12. Wall BM, Mangold T, Huch KM, Corbett C, Cooke CR. Bacteremia in the chronic spinal cord injury population: risk factors for mortality. J Spinal Cord Med 2003;26:248-53. [CrossRef]

13. Ferrell BA, Josephson K, Norvid P, Alcorn H. Pressure ulcers among patients admitted to home care. J Am Geriatr Soc 2000;48:1042-7. [CrossRef] 